\title{
反応性スパッタ法による薄膜 $\mathrm{AlO}_{x}$ を絶縁障壁とする 強磁性トンネル接合の作製*
}

原田 慎也*1 ·椎木 一夫*1

\author{
Study of Spin Tunnel Junctions using $\mathrm{AlO}_{x}$ Insulating \\ Barrier Fabricated by Reactive Sputtering \\ Shinya HARADA*1 and Kazuo SHIIKI*1 \\ ${ }^{*}$ Department of Applied Physics and Physico-Infomatics, Keio University, \\ 3-14-1, Hiyoshi, Kohoku-ku, Yokohama, Kanagawa, 223-8522, Japan
}

(Received October 28, 2004, Accepted May 7, 2005)

\begin{abstract}
The spin tunnel junctions (STJ) using $\mathrm{AlO}_{x}$ insulating barrier layer has been investigated and its composition and electrical characteristic are discussed. The $\mathrm{AlO}_{x}$ insulating barrier layer was fabricated by ion-beam-sputtering $\mathrm{Al}$ with oxygen ions accelerated from assist gun. The barrier height was determined by measuring the current-voltage characteristic of $\mathrm{Co}(10 \mathrm{~nm}) / \mathrm{AlO}_{x} / \mathrm{Co}_{0}(50 \mathrm{~nm}) \mathrm{STJ}$ and fitting the current-voltage curve by Simmons' fitting. It is revealed that varying the oxygen gas flow at the assist gun changed the composition of $\mathrm{AlO}_{x}$ and insulating layer characteristics, which can be explained by Anderson's model. The barrier height also depended on the sputtering time. Furthermore, the noise of STJ fabricated by this method was lower than the noise of STJ using insulating barrier layer fabricated by natural oxidization. From these experimental results, It is expected that by optimizing the oxygen gas flow at the assist gun and the sputtering time, we can obtain $\mathrm{Co} / \mathrm{AlO}_{x} / \mathrm{Co} \mathrm{STJ}$ with high magnetoresistance ratio and low noise.
\end{abstract}

\section{1. はじめに}

高度情報化社会において磁気記録密度の向上が必要とされ ている. その中でトンネル磁気抵抗 (TMR) 効果を用いた TMR 素子の開発が急がれている. TMR 素子は強磁性層/絶 縁層/強磁性層から構成され, 絶縁層としては薄膜 $\mathrm{AlO}_{x}$ が 用いられる事が多い1).

この絶縁層薄膜 $\mathrm{AlO}_{x}$ の作製法としては自然酸化法2)やプ ラズマ酸化法3,4)など様々な方法が試みられているが，これ らの手法は酸化させる $\mathrm{Al}$ 原子層が下部強磁性層の Grain を 反映した構造を有することがわかっており, $\mathrm{Al}$ 原子の酸化 がこの Grain boundary から始まるため, 酸化不均一が生じ る問題がある5).

著者らは, デュアルビームイオンスパッタ法を用いて金属 ターゲット $\mathrm{Al}$ のスパッタによる成膜を行う際に, アシスト ガンから印加電圧 $500 \mathrm{~V}$ で加速させた $\mathrm{O}_{2}$ を流入し, 装置内 で $\mathrm{Al}$ 粒子との酸化反応を促し, $\mathrm{AlO}_{x}$ を作製して成膜を行う 反応性スパッタ法を提案した.

本研究では同方法によって作製された薄膜 $\mathrm{AlO}_{x}$ について 組成および結合状態の分析と障壁高さの測定を通して, 反応 性スパッタ法による絶縁層薄膜 $\mathrm{AlO}_{x}$ の物性と同薄膜を絶縁 障壁とする $\mathrm{Co} / \mathrm{AlO}_{x} / \mathrm{Co}$ スピントンネル接合の特性について 調べた.

\section{2. 実験方法}

デュアルビームイオンスパッタ装置の概略図を Fig. 1 に 示す．スパッタリングガスには Ar ガス（純度 $99.9 \%$ ）を用

\footnotetext{
* 平成16年10月 28 日 第 45 回真空に関する連合講演会において 発表

*1 $_{1}$ 慶應義塾大学大学院理工学研究科（干223-8522 神奈川県横浜 市港北区日吉 3-14-1)
}

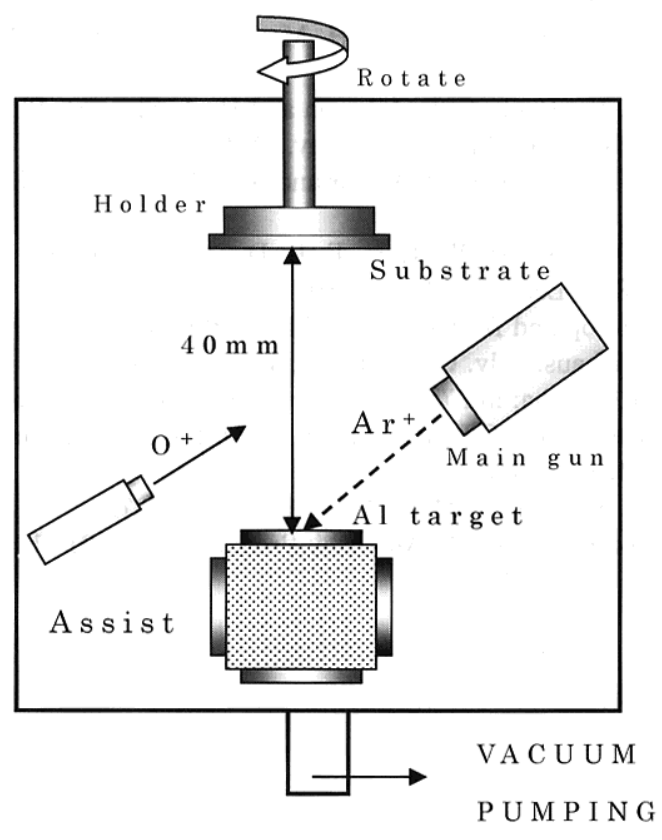

S Y S T E M

Fig. 1 Schematic diagram of dual ion-beam sputtering system.

い，ガス流量は $20 \mathrm{sccm}$ 一定とした. ターゲットには $\mathrm{Al}$ お よび Co（純度 $99.99 \%$, 直径 $154 \mathrm{~mm}$, 厚さ $5 \mathrm{~mm}$ ）を用い た. 槽内の到達真空度は約 $1.16 \times 10^{-5} \mathrm{~Pa}$ であり, スパッタ 中の真空度は約 $6.39 \times 10^{-3} \mathrm{~Pa}$ であった. 基板温度, ターゲ ットー基板間距離, $\mathrm{Ar}$ ガスの加速電圧はそれぞれ室温, 40 $\mathrm{mm}, 1.25 \mathrm{kV}$ とした。 マスクスパッタ法を用いて Co (10 $\mathrm{nm}) / \mathrm{AlO}_{x} / \mathrm{Co}(50 \mathrm{~nm})$ 型スピントンネル素子および Co $(10$ $\mathrm{nm}) / \mathrm{AlO}_{x}$ ，積層試料を基板上に作製した．基板は Corning 社の1753ガラス基板を用いた. $\mathrm{Al}$ 成膜時にアシストガンか 
ら槽内に流す $\mathrm{O}_{2}$ (純度 $99.999 \%$ ) の流量は $0.5 \mathrm{sccm}$ から 5.0 $\mathrm{sccm}$ まで変化させ, 加速電圧を $500 \mathrm{~V}$ に一定に保ち $\mathrm{AlO}_{x}$ 絶 縁層を形成した．この時のスパッタ時間は $40 \mathrm{sec}$. から 180 sec. までとした. 絶縁層の組成評価および化学結合状態の分 析には $\mathrm{Co} / \mathrm{AlO}_{x}$, 積層試料を用いて $\mathrm{X}$ 線光電子分光法 (XPS, $\mathrm{AlK} \alpha)$ によって測定した. 組成は $\mathrm{O}$ 原子と $\mathrm{Al}$ 原子 の原子数比をピークエリアから求め, 標準試料サファイア $\left(\mathrm{Al}_{2} \mathrm{O}_{3}\right)$ と比較する事で $\mathrm{O} / \mathrm{Al}$ ratio を算出して評価した. 同時に $\mathrm{Ar}^{+}$イオンスパッタエッチングによる, $\mathrm{Al} 2 \mathrm{p}$ と $\mathrm{O} 1 \mathrm{~s}$ スペクトルの Depth profiling を行い, 深さ方向についての

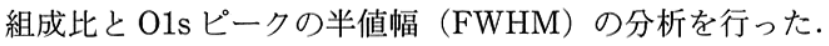
また, $\mathrm{Co} / \mathrm{AlO}_{x} / \mathrm{Co}$ スピントンネル素子について室温中直流 4 端子法による電流電圧特性測定を行い, Simmons' fitting により絶縁層の障壁高さと膜厚を算出した.

\section{3. 実験結果および考察}

$\mathrm{O}_{2}$ 流入量変化による $\mathrm{Al} 2 \mathrm{p}$ スペクトル変化を Fig. 2 に示 す. 流量が $0.5 \mathrm{sccm}$ 以下の時, Bindeng energy が $72.7 \mathrm{eV}$ 付近において $\mathrm{Al}-\mathrm{Al}$ スペクトルが観測された。 また， $\mathrm{Al}-\mathrm{Al}$ スペクトルエリアと $\mathrm{Al}-\mathrm{O}$ スペクトルエリアの比（ $\mathrm{Al}-\mathrm{Al} / \mathrm{Al}$ $-\mathrm{O}$ ratio）と $\mathrm{O}_{2}$ 流量の関係を Fig. 3 に示す. 流入 $\mathrm{O}_{2}$ 増加 に従って直線的に未酸化 $\mathrm{Al}$ が減少している事がわかった. これらの未酸化 $\mathrm{Al}$ が存在する $\mathrm{AlO}_{x}$ を絶縁障壁とする $\mathrm{Co} /$ $\mathrm{AlO}_{x} / \mathrm{Co}$ スピントンネル素子ではトンネル電流は観測され

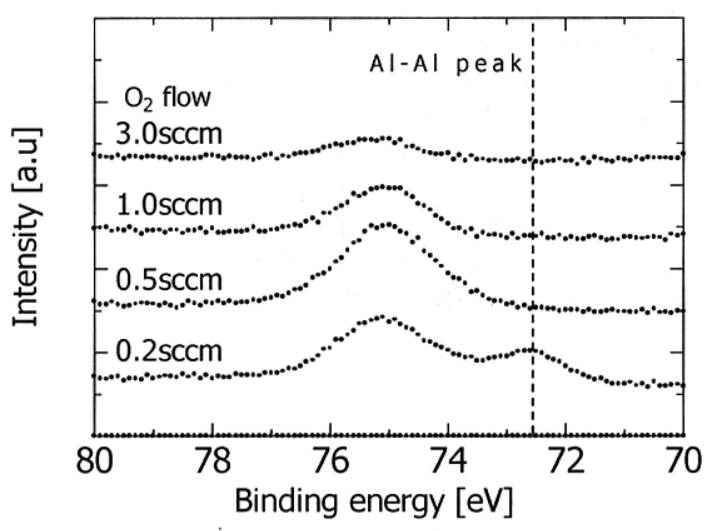

Fig. 2 Effect of $\mathrm{O}_{2}$ flow on $\mathrm{Al} 2 \mathrm{p}$ spectra of $\mathrm{AlO}_{x}$ layers.

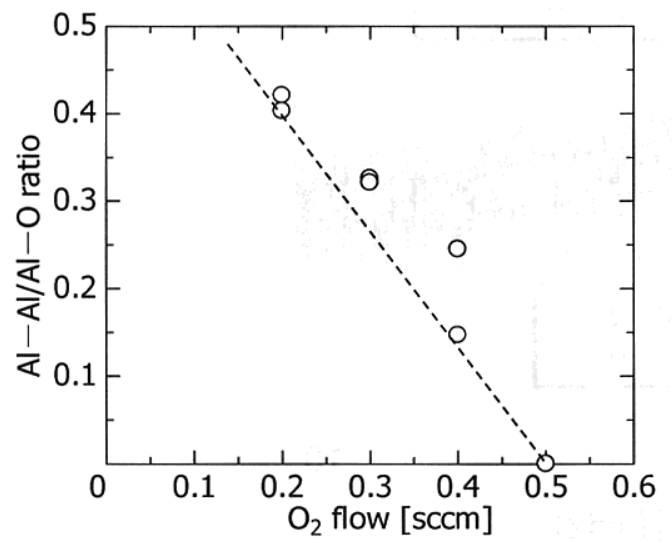

Fig. 3 Relationship between $\mathrm{O}_{2}$ flow and $\mathrm{Al}-\mathrm{Al} / \mathrm{Al}-\mathrm{O}$ ratio for reactive sputtered $\mathrm{AlO}_{x}$ films.
ず, 接合部電圧の増加に伴い, 電流の減少する金属的な電流 電圧特性を示した.

$0.5 \mathrm{sccm}$ 以上の $\mathrm{O}_{2}$ 流入と組成比 $\mathrm{O} / \mathrm{Al}$ ratio $の$ 関係を Fig. 4 に示す. $\mathrm{O}_{2}$ 流入量の増加が $\mathrm{AlO}_{x}$ の過酸化を促す事 がわかった。 また，この $\mathrm{O} / \mathrm{Al}$ ratioについて Depth profile した結果を Fig. 5 に示す．深さ方向に ratioの変動はほとん ど見られず，均一に酸化した絶縁層が一様に成膜されている 事がわかった． O/Al ratio と絶縁層の障壁高さの関係を Fig. 6 に示す.これは $\mathrm{AlO}_{x}$ の過酸化に従って絶縁性が低下

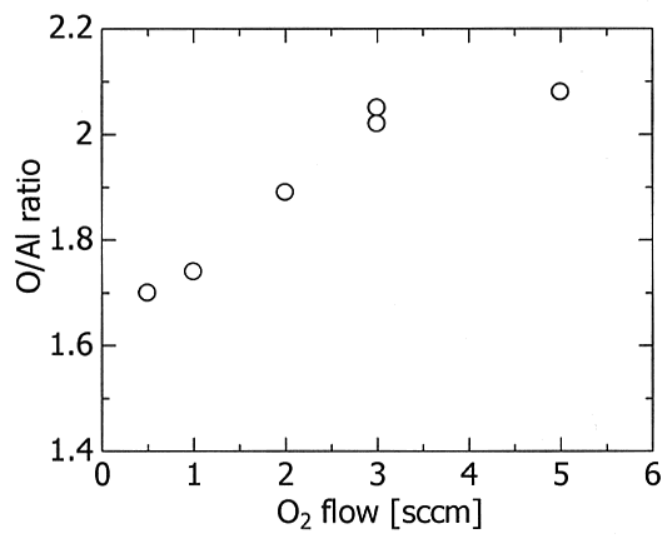

Fig. 4 Relationship between $\mathrm{O}_{2}$ flow and $\mathrm{O} / \mathrm{Al}$ ratio for reactive sputtered $\mathrm{AlO}_{x}$ films.

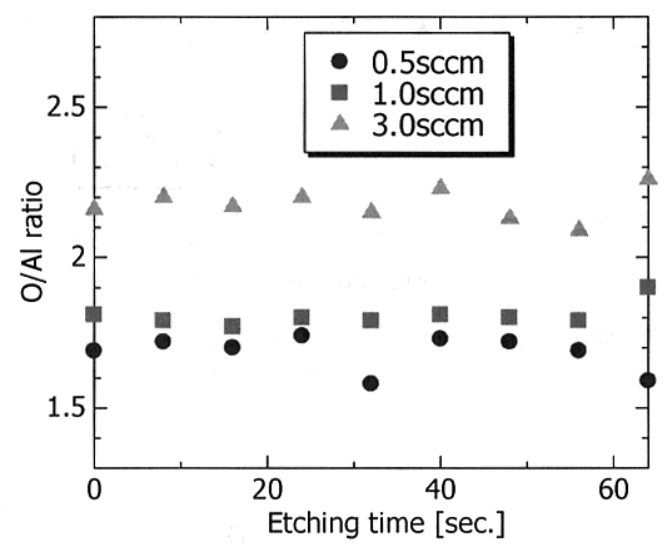

Fig. 5 Depth profiles $\mathrm{O} / \mathrm{Al}$ ratio for sputtered $\mathrm{AlO}_{x}$ films.

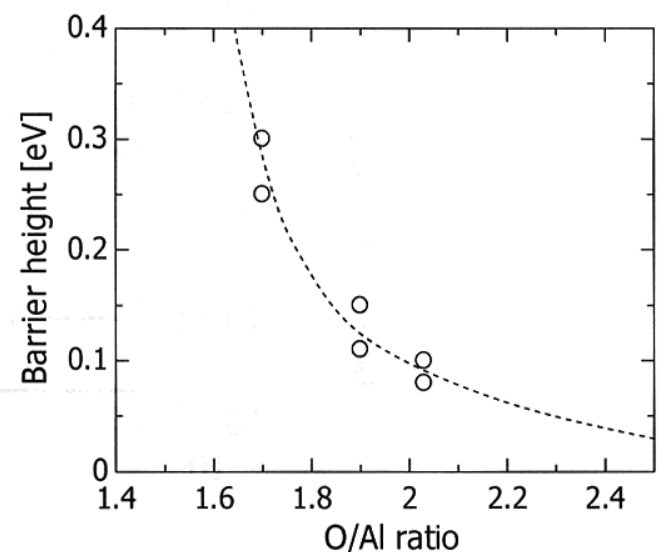

Fig. 6 Relationship between $\mathrm{O} / \mathrm{Al}$ ratio and barrier height for reactive sputtered $\mathrm{AlO}_{x}$ films. 
している事を意味している.これら過酸化 $\mathrm{AlO}_{x}$ 薄膜につい て Al2p スペクトルの半值幅 (FWHM) をDepth profile し た結果を Fig. 7 に示す. $\mathrm{O}_{2}$ 流量の增加に伴って FWHM は 上昇の傾向を示す。これは絶縁層内の $\mathrm{Al}-\mathrm{O}$ 結合の Binding energy は広範囲に存在している事を示している. XPS 分析 における Binding energy は最外殼からフェルミ準位までの エネルギーであり，バンドギャップに相当する．これが広範 囲である事は $\mathrm{AlO}_{x}$ のバンドギャップが一定の幅を有してい る事を意味する. Anderson 局在 ${ }^{6}$ によると非晶質物質はバ ンドギャップの深さがランダムになるに従って, 強束䌮近似 が可能な結晶格子に比べ状態密度が広くなり, 絶縁性が減少 する. $\mathrm{AlO}_{x}$ の過酸化によって絶縁珄が低下する事はこれか ら説明が可能であると考えられる.

この最も絶縁性が高い $0.5 \mathrm{sccm}$ の $\mathrm{O}_{2}$ 流入条件下において,

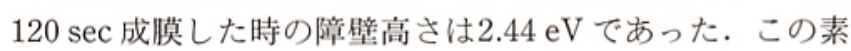
子に電圧を印加した時のトンネル電流ノイズを測定した結果 をFig. 8 に示す. 自然酸化法と比較してトンネル抵抗は 20 倍近いにもかかわらず, 周波数特性の直線近似から以下の式 で定義される雑音係数について

$$
\frac{1}{f}=\beta \frac{(R I)^{2}}{f^{\alpha}}
$$

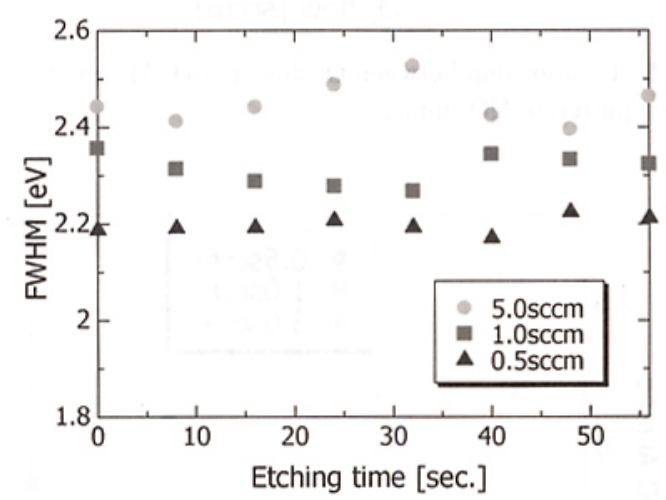

Fig. 7 Depth profiles FWHM of XPS Al2p spectra for reactive sputtered $\mathrm{AlO}_{x}$ films fabricated with different $\mathrm{O}_{2}$ flows.
( $f:$ 周波数 $I:$ センス電流 $\alpha, \beta$ は雑音係数) 自然酸化が $\alpha=1.12 \beta=7.3 \times 10^{-9}$, 反応性スパッタ法では $\alpha$ $=0.86 \beta=1.1 \times 10^{-11}$ と 2 桁小さいオーダーを得た. 雑音係 数は不均一な混合材料の粒子や構造によって決定する事が報 告されており7), 反応性スパッタ法による絶縁層が一様な構 造をしている事が実用上で問題とされている雑音低減の理由 であると考えられる.

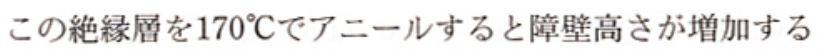
事を確認した. 今後, 表面処理をはじめ成膜真空度の向上や 加速電圧の最適化で一層良質な薄膜 $\mathrm{AlO}_{x}$ が得られる事が期 待でき, 高磁気抵抗比を有する強磁性トンネル接合の作製が 可能であると考える.

\section{4. まとめ}

本研究では反応性スパッタ法による $\mathrm{AlO}_{x}$ を絶縁障壁とす る $\mathrm{Co} / \mathrm{AlO}_{x} / \mathrm{Co}$ スピントンネル素子の作製と測定を行った. 結果として流入 $\mathrm{O}_{2}$ によって $\mathrm{AlO}_{x}$ の組成が変化し, それに 対応して絶縁層の障壁高さは変化する.この現象は Anderson 局在によって説明が可能である. また, トンネル雑音は 自然酸化よりも低減している事を確認した．これらの結果か ら，最適条件で成膜した絶縁層を用いる事で高 MR 比で低 ノイズな TMR 素子の作製が期待できる.

\section{〔文献〕}

1）沢崎立雄, 森口晃治, 山崎䇥志, 田ノ上修二 : 日本応用磁気学 会誌, 23 (1999) 1293.

2) H. Kaiju, K. Shiiki, S. Fujita and T. Morozumi: Jpn. J. Appl. Phys., 42 (2003) 1246.

3) M. Tsunoda et al.: Appl. Phys. Lett., 80 (2002) 6061.

4) E. Y. Chen et al.: J. Appl. Phys., 87 (2000) 661.

5）矢尾板和也, 上篠 誠, 新関智彦, 山本直志, 久保田均, 安藤 康夫, 宮崎照宣：日本応用磁気学会誌， 25 (2002) 771.

6) P. W. Anderson: Phys. Rev., B109 (1958) 1786.

7）西村真一, 平林直明, 海住英夫, 椎木一夫 : 日本応用磁気学会 学術講演会概要集, $16 \mathrm{aE}-8$ (2003) 85 .

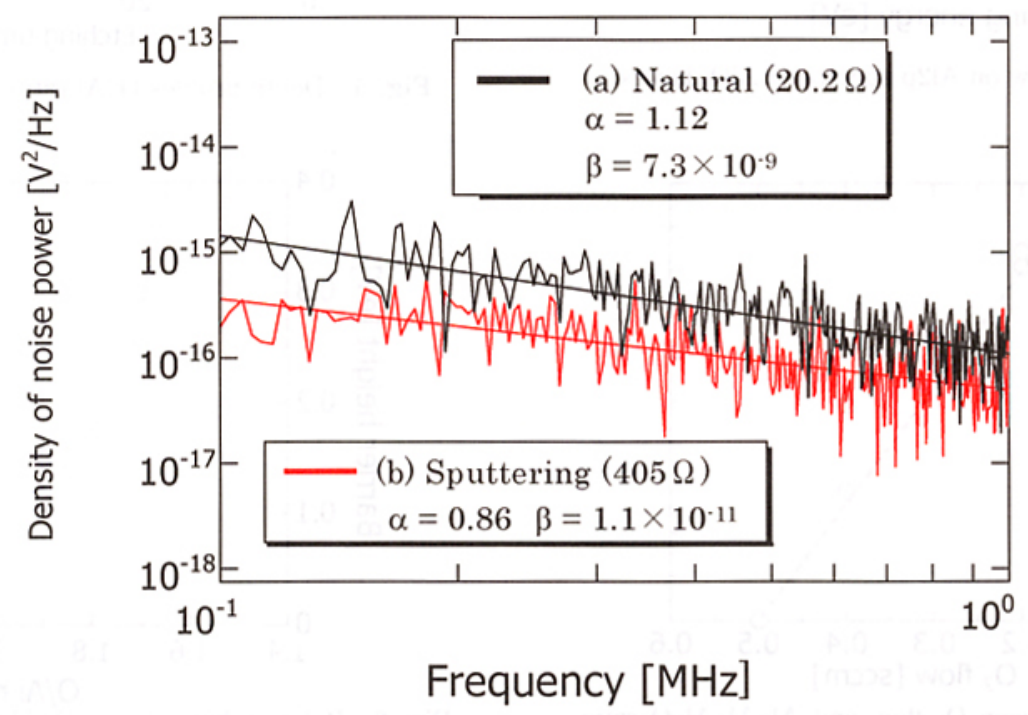

Fig. 8 Results of measuring noise of STJ using $\mathrm{AlO}_{x}$ layer fabricated by different methods. 